\title{
AKTUALISASI NILAI PANCASILA DALAM KEHIDUPAN BERBANGSA DAN BERNEGARA
}

\author{
Oleh: \\ I Wayan Tagel Eddy \\ Fakultas Ilmu Budaya Universitas Udayana \\ Denpasar \\ tageleddy58@gmail.com
}

\begin{abstract}
The dynamics in actualizing the value of Pancasila into the life within the society, nationship and citizenship is a necessity, so that Pancasila remains a relevant paradigm in providing guidance for policy making and problem solving in the life of nationship as well as citizenship. Hence, the loyalty of the citizens to Pancasila remains in the high level. On the other hand, apathy and resistance to Pancasila can be minimized. The substance of the dynamics in the actualization of Pancasila values in the life of praxis is always the change and renewal in transforming the value of Pancasila into the norms and practices of life by maintaining consistency, relevance, and contextualization. While continuous change and renewal occurs when there is internal dynamics (self-renewal) and the absorption of foreign values that are relevant for the development and instilment of ideology Pancasila. The outcomes of all efforts to change and renewal in actualizing the value of the Pancasila is the tolerance of acceptability and credibility of Pancasila by the citizens of Indonesia.
\end{abstract}

Keywords: Pancasila value, actualization, nationship, citizenship

\begin{abstract}
Abstrak
Dinamika dalam mengaktualisasikan nilai Pancasila ke dalam kehidupan bermasyarakat, berbangsa, dan benegara adalah suatu keniscayaan, agar Pancasila tetap selalu relevan dalam fungsinya memberikan pedoman bagi pengambilan kebijaksanaan dan pemecahan masalah dalam kehidupan berbangsa dan bernegara. Agar loyalitas warga masyarakat dan warganegara terhadap Pancasila tetap tinggi. Di lain pihak, apatisme dan resistensi terhadap Pancasila bisa diminimalisir. Substansi dari adanya dinamika dalam aktualisasi nilai Pancasila dalam kehidupan praksis adalah selalu terjadinya perubahan dan pembaharuan dalam mentransformasikan nilai Pancasila ke dalam norma dan praktik hidup dengan menjaga konsistensi, relevansi, dan kontekstualisasinya. Sedangkan perubahan dan pembaharuan yang berkesinambungan terjadi apabila ada dinamika internal (selfrenewal) dan penyerapan terhadap nilai-nilai asing yang relevan untuk pengembangan dan penggayaan ideologi Pancasila.Muara dari semua upaya perubahan dan pembaharuan dalam mengaktualisasikan nilai Pancasila adalah terjaganya akseptabilitas dan kredibilitas Pancasila oleh warganegara dan wargamasyarakat Indonesia.
\end{abstract}

Kata Kunci: nilai Pancasila, aktualisasi, berbangsa, bernegara 


\section{PENDAHULUAN}

Aktualisasi Pancasila dalam Kehidupan Berbangsa dan Bernegara dilihat dari aspek (1) Keharusan moral, (2) subyektif, (3) ketaatan moral, (4) kesadaran moral, (5) internalisasi nilai-nilai moral Pancasila, (6) proses pembentukan kepribadian Pancasila, dan (7) implementasi nilai-nilai Pancasila", dapat dijelaskan sebagai berikut.

Pancasila sebagai dasar dan ideologi negara merupakan kesepakatan politik para founding fathers ketika negara Indonesia didirikan. Namun dalam perjalanan panjang kehidupan berbangsa dan bernegara, Pancasila sering mengalami berbagai deviasi dalam aktualisasi nilai-nilainya. Deviasi pengamalan Pancasila tersebutbisaberupa penambahan, pengurangan, dan penyimpangan dari makna yang seharusnya, dan seiring dengan itu sering pula terjadi upaya pelurusan kembali.

Pancasila sering digolongkan ke dalam ideologi tengah di antara dua ideologi besar dunia yang paling berpengaruh, sehingga sering disifatkan bukan ini dan bukan itu. Pancasila bukan berpaham komunisme dan bukan berpaham kapitalisme. Pancasila tidak berpaham individualisme dan tidak berpaham kolektivisme. Bahkan bukan berpaham teokrasi dan bukan perpaham sekuler. Posisi Pancasila inilah yang merepotkan aktualisasi nilai-nilainya ke dalam kehidupan praksis berbangsa dan bernegara. Dinamika aktualisasi nilai Pancasila bagaikan pendelum (bandul jam) yang selalu bergerak ke kanan dan ke kiri secara seimbang tanpa pernah berhenti tepat di tengah.

Pada saat berdirinya negara Republik Indonesia, kita sepakat mendasarkan diri pada ideologi Pancasila dan UUD 1945 dalam mengatur dan menjalankan kehidupan negara. Namun sejak Nopember 1945 sampai sebelum Dekrit Presiden 5 Juli 1959 pemerintah Indonesia mengubah haluan politiknya dengan mempraktikan sistem demokrasi liberal.Dengan kebijakan ini berarti menggerakan pendelum bergeser ke kanan. Pemerintah Indonesia menjadi pro Liberalisme.Deviasi ini dikoreksi dengan keluarnya Dekrit Presiden 5 Juli 1959. Dengan keluarnya Dekrit Presiden ini berartilah haluan politk negara dirubah. Pendelum yang posisinya di samping kanan digeser dan digerakan ke kiri.Kebijakan ini sangat menguntungkan dan dimanfaatkan oleh kekuatan politik di Indonesia yang berhaluan kiri (baca: PKI) Hal ini tampak pada kebijaksanaan pemerintah yang anti terhadap Barat (kapitalisme) dan pro ke Kiri dengan dibuatnya poros Jakarta-Peking dan JakartaPyong Yang. Puncaknya adalah peristiwa pemberontakan Gerakan 30 September 1965. Peristiwa ini menjadi pemicu tumbangnya pemerintahan Orde Lama (Ir.Soekarno) dan berkuasanya pemerintahan Orde Baru (Jenderal Suharto). Pemerintah Orde Baru berusaha mengoreksi segala penyimpangan yang dilakukan oleh regim sebelumnya dalam pengamalan Pancasila dan UUD 1945. Pemerintah Orde Baru merubah haluan politik yang tadinya mengarah ke posisi Kiri dan anti Barat menariknya ke posisi Kanan. Namun regim Orde Barupun akhirnya dianggap penyimpang dari garis politik Pancasila dan UUD 1945, Ia dianggap cenderung ke praktik Liberalisme-kapitalistik dalam menggelola negara. Pada tahun 1998 muncullah gerakan reformasi yang dahsyat dan berhasil mengakhiri 32 tahun kekuasaan Orde Baru. Setelah tumbangnya regim Orde Baru telah muncul 4 regim Pemerintahan Reformasi sampai saat ini. Pemerintahan-pemerintahan regim Reformasi ini semestinya mampu memberikan koreksi terhadap penyimpangan dalam mengamalkan Pancasila dan UUD 1945 dalam praktik bermasyarakat dan bernegara yang dilakukan oleh Orde Baru.

\section{Aktualisasi Nilai Pancasila}

\subsection{Kerangka Teoritik}

Alfred North Whitehead (1864 - 1947), tokoh utama filsafat proses, berpandangan bahwa semua realitas dalam alam mengalami proses atau perubahan, yaitu kemajuan, kreatif dan baru. Realitas itu dinamik dan suatu proses yang terus menerus "menjadi", walaupun unsur permanensi realitas dan identitas diri dalam perubahan tidak boleh diabaikan. Sifat alamiah itu dapat pula dikenakan pada ideologi Pancasila sebagai suatu realitas (pengada). Masalahnya, bagaimanakah nilai-nilai Pancasila itu diaktualisasikan dalam praktik kehidupan berbangsa dan bernegara ? dan, unsur nilai Pancasila manakah yang mesti harus kita pertahankan tanpa mengenal perubahan ? 
Moerdiono (1995/1996) menunjukkan adanya 3 tataran nilai dalam ideologi Pancasila. Tiga tataran nilai itu adalah:

Pertama, nilai dasar, yaitu suatu nilai yang bersifat amat abstrak dan tetap, yang terlepas dari pengaruh perubahan waktu.Nilai dasar merupakan prinsip, yang bersifat amat abstrak, bersifat amat umum, tidak terikat oleh waktu dan tempat, dengan kandungan kebenaran yang bagaikan aksioma.Dari segi kandungan nilainya, maka nilai dasar berkenaan dengan eksistensi sesuatu, yang mencakup cita-cita, tujuan, tatanan dasar dan ciri khasnya. Nilai dasar Pancasila ditetapkan oleh para pendiri negara. Nilai dasar Pancasila tumbuh baik dari sejarah perjuangan bangsa Indonesia melawan penjajahan yang telah menyengsarakan rakyat, maupun dari cita-cita yang ditanamkan dalam agama dan tradisi tentang suatu masyarakat yang adil dan makmur berdasarkan kebersamaan, persatuan dan kesatuan seluruh warga masyarakat.

Kedua, nilai instrumental, yaitu suatu nilai yang bersifat kontekstual. Nilai instrumental merupakan penjabaran dari nilai dasar tersebut, yang merupakan arahan kinerjanya untuk kurun waktu tertentu dan untuk kondisi tertentu. Nilai instrumental ini dapat dan bahkan harus disesuaikan dengan tuntutan zaman. Namun nilai instrumental haruslah mengacu pada nilai dasar yang dijabarkannya. Penjabaran itu bisa dilakukan secara kreatif dan dinamik dalam bentuk-bentuk baru untuk mewujudkan semangat yang sama, dalam batas-batas yang dimungkinkan oleh nilai dasar itu.Dari kandungan nilainya, maka nilai instrumental merupakan kebijaksanaan, strategi, organisasi, sistem, rencana, program, bahkan juga proyekproyek yang menindaklanjuti nilai dasar tersebut. Lembaga negara yang berwenang menyusun nilai instrumental ini adalah MPR, Presiden, dan DPR.

Ketiga, nilai praksis, yaitu nilai yang terkandung dalam kenyataan sehari-hari, berupa cara bagaimana rakyat melaksanakan (mengaktualisasikan) nilai Pancasila. Nilai praksis terdapat pada demikian banyak wujud penerapan nilai-nilai Pancasila, baik secara tertulis maupun tidak tertulis, baik oleh cabang eksekutif, legislatif, maupun yudikatif, oleh organisasi kekuatan sosial politik, oleh organisasi kemasyarakatan, oleh badan-badan ekonomi, oleh pimpinan kemasyarakatan, bahkan oleh warganegara secara perseorangan. Dari segi kandungan nilainya, nilai praksis merupakan gelanggang pertarungan antara idealisme dan realitas.

Jika ditinjau dari segi pelaksanaan nilai yang dianut, maka sesungguhnya pada nilai praksislah ditentukan tegak atau tidaknya nilai dasar dan nilai instrumental itu. Ringkasnya bukan pada rumusan abstrak, dan bukan juga pada kebijaksanaan, strategi, rencana, program atau proyek itu sendiri terletak batu ujian terakhir dari nilai yang dianut, tetapi pada kualitas pelaksanaannya di lapangan. Bagi suatu ideologi, yang paling penting adalah bukti pengamalannya atau aktualisasinya dalam kehidupan bermasyarakat, berbangsa, dan bernegara. Suatu ideologi dapat mempunyai rumusan yang amat ideal dengan ulasan yang amat logis serta konsisten pada tahap nilai dasar dan nilai instrumentalnya. Akan tetapi, jika pada nilai praksisnya rumusan tersebut tidak dapat diaktualisasikan, maka ideologi tersebut akan kehilangan kredibilitasnya.Bahkan Moerdiono (1995/1996: 15) menegaskan, bahwa bahwa tantangan terbesar bagi suatu ideologi adalah menjaga konsistensi antara nilai dasar, nilai instrumental, dan nilai praksisnya. Sudah barang tentu jika konsistensi ketiga nilai itu dapat ditegakkan, maka terhadap ideologi itu tidak akan ada masalah. Masalah baru timbul jika terdapat inkonsisitensi dalam tiga tataran nilai tersebut.

Untuk menjaga konsistensi dalam mengaktualisasikan nilai Pancasila ke dalam praktik hidup berbangsa dan bernegara, maka perlu Pancasila formal yang abstrak-umumuniversal itu ditransformasikan menjadi rumusan Pancasila yang umum kolektif, dan bahkan menjadi Pancasila yang khusus individual (Suwarno, 1993: 108). Artinya, Pancasila menjadi sifat-sifat dari subjek kelompok dan individual, sehingga menjiwai semua tingkah laku dalam lingkungan praksisnya dalam bidang kenegaraan, politik, dan pribadi.

Driyarkara menjelaskan proses pelaksanaan ideologi Pancasila, dengan gambaran gerak transformasi Pancasila formal sebagai kategori tematis (berupa konsep, teori) menjadi kategori imperatif (berupa norma-norma) dan kategori operatif (berupa praktik hidup). Proses tranformasi berjalan tanpa masalah apabila 
tidak terjadi deviasi atau penyimpangan, yang berupa pengurangan, penambahan,dan penggantian (dalam Suwarno, 1993: 110-111). Operasionalisasi Pancasila dalam kehidupan bermasyarakat, berbangsa dan bernegara haruslah diupayakan secara kreatif dan dinamik, sebab Pancasilasebagai ideologi bersifat futuralistik. Artinya, nilai-nilai yang terkandung dalam Pancasila merupakan nilai-nilai yang dicita-citakan dan ingin diwujudkan.

Masalah aktualisasi nilai-nilai dasar ideologi Pancasila ke dalam kehidupan praksis kemasyarakatan dan kenegaraan bukanlah masalah yang sederhana. Soedjati Djiwandono (1995: 2-3) mensinyalir, bahwa masih terdapat beberapa kekeliruan yang mendasar dalam cara orang memahami dan menghayati Negara Pancasila dalam berbagai seginya. Kiranya tidak tepat membuat "sakral" dan taboo berbagai konsep dan pengertian, seakan-akan sudah jelas betul dan pasti benar, tuntas dan sempurna, sehingga tidak boleh dipersoalkan lagi. Sikap seperti itu membuat berbagai konsep dan pengertian menjadi statik, kaku dan tidak berkembang, dan mengandung resiko ketinggalan zaman, meskipun mungkin benar bahwa beberapa prinsip dasar memang mempunyai nilai yang tetap dan abadi. Belum teraktualisasinya nilai dasar Pancasila secara konsisten dalam tataran praksis perlu terus menerus diadakan perubahan, baik dalam arti konseptual maupun operasional. Banyak hal harus ditinjau kembali dan dikaji ulang. Beberapa mungkin perlu dirubah, beberapa lagi mungkin perlu dikembangkan lebih lanjut dan dijelaskan atau diperjelas, dan beberapa lagi mungkin perlu ditinggalkan.

Aktualisasi nilai Pancasila dituntut selalu mengalami pembaharuan. Hakikat pembaharuan adalah perbaikan dari dalam dan melalui sistem yang ada. Atau dengan kata lain, pembaharuan mengandaikan adanya dinamika internal dalam diri Pancasila. Mengunakan pendekatan teori Aristoteles, bahwa di dalam diri Pancasila sebagai pengada (realitas) mengandung potensi, yaitu dasar kemungkinan (dynamik). Potensi dalam pengertian ini adalah kemampuan real subjek (dalam hal ini Pancasila) untuk dapat berubah. Subjek sendiri yang berubah dari dalam. Mirip dengan teori A.N.Whitehead, setiap satuan aktual (sebagai aktus, termasuk Pancasila) terkandung daya kemungkinan untuk berubah. Bukan kemungkinan murni logis atau kemungkinan objektif, seperti batu yang dapat dipindahkan atau pohon yang dapat dipotong. Bagi Whitehead, setiap satuan aktual sebagai realitas merupakan sumber daya untuk proses kemenjadi-an yang selanjutnya. Jika dikaitkan dengan aktualisasi nilai Pancasila, maka pada dasarnya setiap ketentuan hukum dan perundang-undangan pada segala tingkatan, sebagai aktualisasi nilai Pancasila (transformasi kategori tematis menjadi kategori imperatif), harus terbuka terhadap peninjauan dan penilaian atau pengkajian tentang keterkaitan dengan nilai dasar Pancasila.

Untuk melihat transformasi Pancasila menjadi norma hidup sehari-hari dalam bernegara orang harus menganalisis pasal-pasal penuangan sila ke-4 yang berkaitan dengan negara, yang meliputi; wilayah, warganegara, dan pemerintahan yang berdaulat. Selanjutnya, untuk memahami transformasi Pancasila dalam kehidupan berbangsa, orang harus menganalisis pasal-pasal penuangan sila ke-3 yang berkaitan dengan bangsa Indonesia, yang meliputi; faktorfaktor integratif dan upaya untuk menciptakan persatuan Indonesia. Sedangkan untuk memahami transformasi Pancasila dalam kehidupan bermasyarakat, orang harus menganalisis pasal-pasal penuangan sila ke-1, ke-2, dan ke-5 yang berkaitan dengan hidup keagamaan, kemanusiaan dan sosial ekonomis (Suwarno, 1993: 126).

\subsection{Perubahan dan Kebaharuan}

Pembaharuan dan perubahan bukanlah melulu bersumber dari satu sisi saja, yaitu akibat yang timbul dari dalam, melainkan bisa terjadi karena pengaruh dari luar. Terjadinya proses perubahan (dinamika) dalam aktualisasi nilai Pancasila tidaklah semata-mata disebabkan kemampuan dari dalam (potensi) dari Pancasila itu sendiri, melainkan suatu peristiwa yang terkait atau berrelasi dengan realitas yang lain. Dinamika aktualisasi Pancasila bersumber pada aktivitas di dalam menyerap atau menerima dan menyingkirkan atau menolak nilai-nilai atau unsur-unsur dari luar (asing). Contoh paling jelas dari terjadinya perubahan transformatif dalam aktualisasi nilai Pancasila dalam kehidupan bermasyarakat, berbangsa dan bernegara, adalah empat kali amandemen UUD 
1945 yang telah dilakukan MPR pada tahun 1999, 2000, 2001, dan tahun 2002.

Dewasa ini, akibat kemajuan ilmu dan teknologi, khususnya teknologi komunikasi, terjadilah perubahan pola hidup masyarakat yang begitu cepat. Tidak satupun bangsa dan negara mampu mengisolir diri dan menutup rapat dari pengaruh budaya asing. Demikian juga terhadap masalah ideologi.Dalam kaitan imi, M.Habib Mustopo (1992: 11 -12) menyatakan, bahwa pergeseran dan perubahan nilai-nilai akan menimbulkan kebimbangan, terutama didukung oleh kenyataan masuknya arus budaya asing dengan berbagai aspeknya. Kemajuan di bidang ilmu dan teknologi komunikasi \& transportasi ikut mendorong hubungan antar bangsa semakin erat dan luas. Kondisi ini di satu pihak akan menyadarkan bahwa kehidupan yang mengikat kepentingan nasional tidak luput dari pengaruhnya dan dapat menyinggung kepentingan bangsa lain. Ada semacam kearifan yang harus dipahami, bahwa dalam kehidupan dewasa ini, teknologi sebagai bagian budaya manusia telah jauh mempengaruhi tata kehidupan manusia secara menyeluruh. Dalam keadaan semacam ini, tidak mustahiltumbuh suatu pandangan kosmopolitan yang tidak selalu sejalan dengan tumbuhnya faham kebangsaan.Beberapa informasi dalam berbagai ragam bentuk dan isinya tidak dapat selalu diawasi atau dicegah begitu saja. Mengingkari dan tidak mau tahu "tawaran" atau pengaruh nilai-nilai asing merupakan kesesatan berpikir, yang seolah-olah menganggap bahwa ada eksistens yang bisa berdiri sendiri. Kesalahan berpiklir demikian oleh Whitehead disebut sebagai the fallacy of misplace concretness (Damardjati Supadjar, 1990: 68). Jika pengaruh itu tidak sesuai dengan nilai-nilai yang hidup dalam masyarakat, atau tidak mendukung bagi terciptanya kondisi yang sesuai dengan Pancasila, maka perlu dikembangkan sikap yang kritis terutama terhadap gagasan-gagasan, ideide yang datang dari luar.

Dalam konteks budaya, masalah pertemuan kebudayaan bukan masalah memfilter atau menyaring budaya asing, tetapi mengolah dan mengkreasi dalam interaksi dinamik sehingga tercipta sesuatu yang baru. Jati diri bangsa, budaya politik adalah sesuatu yang harus terus menerus dikonstruksikan, karena bukan kenyataan yang mandeg (Sastrapratedja, 1996:
11). Kalau ideologi-ideologi besar di dunia sekarang ini diperhatikan dengan seksama, maka terlihat mereka bergeser secara dinamik. Para penyangga ideologi itu telah melakukan revisi, pembaharuan, dan pemantapanpemantapan dalam mengaktualisasikan ideologinya. Perkembangan zaman menuntut bahwa ideologi harus memiliki nafas baru, semangat baru dengan corak nilai, ajaran dan konsep kunci mengenai kehidupan yang memiliki perspektif baru. Ideologi Pancasilapun dituntut demikian. Pancasila harus mampu menghadapi pengaruh budaya asing, khususnya ilmu dan teknologi modern dan latar belakang filsafatnya yang berasal dari luar.

Prof. Notonagoro telah menemukan cara untuk memanfaatkan pengaruh dari luar tersebut, yaitu secara eklektif mengambil ilmu pengetahuan dan ajaran kefilsafatan dari luar tersebut, tetapi dengan melepaskan diri dari sistem filsafat yang bersangkutan dan selanjutnya diinkorporasikan dalam struktur filsafat Pancasila. Dengan demikian, terhadap pengaruh baru dari luar, maka Pancasila bersifat terbuka dengan syarat dilepaskan dari sistem filsafatnya, kemudian dijadikan unsur yang serangkai dan memperkaya struktur filsafat Pancasila (Sri Soeprapto, 1995: 34). Sepaham dengan Notonagoro, Dibyasuharda (1990: 229) mengkualifikasikan Pancasila sebagai struktur atau sistem yang terbuka dinamik, yang dapat menggarap apa yang datang dari luar, dalam arti luas, menjadi miliknya tanpa mengubah identitasnya, malah mempunyai daya ke luar, mempengaruhi dan mengkreasi.

Dinamika Pancasila dimungkinkan apabila ada daya refleksi yang mendalam dan keterbukaan yang matang untuk menyerap, menghargai, dan memilih nilai-nilai hidup yang tepat dan baik untuk menjadi pandangan hidup bangsa bagi kelestarian hidupnya di masa mendatang. Sedangkan penerapan atau penolakan terhadap nilai-nilai budaya luar tersebut berdasar pada relevansinya. Dalam konteks hubungan internasional dan pengembangan ideologi, bukan hanya Pancasila yang menyerap atau dipengaruhi oleh nilai-nilai asing, namun nilai-nilai Pancasila bisa ditawarkan dan berpengaruh, serta menyokong kepada kebudayaan atau ideologi lain. Bahkan Soerjanto Poespowardojo (1989: 14) menjelaskan, bahwa dinamika yang ada pada 
aktualisasi Pancasila memungkinkan bahwa Pancasila juga tampil sebagai alternatif untuk melandasi tata kehidupan internasional, baik untuk memberikan orientasi kepada negaranegara berkembang pada khususnya, maupun mewarnai pola komunikasi antar negara pada umumnya.

Ideologi Pancasila bukanlah pseudo religi. Oleh karena itu, Pancasila perlu dijabarkan secara rasional dan kritis agar membuka iklim hidup yang bebas dan rasional pula. Konsekuensinya, bahwa Pancasila harus bersifat terbuka. Artinya, peka terhadap perubahan yang terjadi dalam kehidupan manusia dan tidak menutup diri terhadap nilai dan pemikiran dari luar yang memang diakui menunjukkan arti dan makna yang positif bagi pembinaan budaya bangsa, sehingga dengan demikian menganggap proses akulturasi sebagai gejala wajar. Dengan begitu ideologi Pancasila akan menunjukkan sifatnya yang dinamik, yaitu memiliki kesediaan untuk mengadakan pembaharuan yang berguna bagi perkembangan pribadi manusia dan masyarakat. Untuk menghadapi tantangan masa depan perlu didorong pengembangan nilai-nilai Pancasila secara kreatif dan dinamik. Kreativitas dalam konteks ini dapat diartikan sebagai kemampuan untuk menyeleksi nilai-nilai baru dan mencari alternatif bagi pemecahan masalahmasalah politik, sosial, budaya, ekonomi, dan pertahanan keamanan. Ideologi Pancasila tidak a priori menolak bahan-bahan baru dan kebudayaan asing, melainkan mampu menyerap nilai-nilai yang dipertimbangkan dapat memperkaya dan memperkembangkan kebudayaan sendiri, serta mempertinggi derajat kemanusiaan bangsa Indonesia. Menurut Hardono Hadi (1994: 57), bangsa Indonesia, sebagai pengemban ideeologi Pancasila, tidak defensif dan tertutup sehingga sesuatu yang berbau asing harus ditangkal dan dihindari karena dianggap bersifat negatif. Sebaliknya tidak diharapkan bahwa bangsa Indonesia menjadi begitu amorf, sehingga segala sesuatu yang menimpa dirinya diterima secara buta tanpa pedoman untuk menentukan mana yang pantas dan mana yang tidak pantas untuk diintegrasikan dalam pengembangan dirinya.

Bangsa Indonesia mau tidak mau harus terlibat dalam dialog dengan bangsa-bangsa lain, namun tidak tenggelam dan hilang di dalamnya. Proses akulturasi tidak dapat dihindari. Bangsa Indonesia juga dituntut berperan aktif dalam pergaulan dunia.Bangsa Indonesia harus mampu ikut bermain dalam interaksi mondial dalam menentukan arah kehidupan manusia seluruhnya. Untuk bisa menjalankan peran itu, bangsa Indonesia sendiri harus mempunyai kesatuan nilai yang menjadi keunikan bangsa, sehingga mampu memberikan sumbangan yang cukup berarti dalam percaturan internasional. Identitas diri bukan sesuatu yang tertutup tetapi sesuatu yang terus dibentuk dalam interaksi dengan kelompok masyarakat bangsa, negara, manusia, sistem masyarakat dunia (Sastrapratedja, 1996: 3).

Semuanya itu mengharuskan adanya strategi kebudayaan yang mampu neneruskan dan mengembangkan nilai-nilai luhur Pancasila dalam segala aspek kehidupan bangsa.

Abdulkadir Besar (1994: 35) menawarkan pelaksanaan "strategi dialogi antar budaya" dalam menghadapi gejala penyeragaman atau globalisasi dewasa ini.. Artinya, membiarkan budaya asing yang mengglobal berdampingan dengan budaya asli. Melalui interaksi yang terus menerus, masing-masing budaya akan mendapatkan pelajaran yang berharga. Hasil akhir yang diharapkan dari interaksi itu adalah terpeliharanya cukup diferensiasi, sekaligus tercegahnya penyeragaman universal. Ideologi Pancasila sebagai jati diri bangsa Indonesia tidak mandeg, melainkan harus diperbaharui secara terus menerus, sehingga mampu memberikan pedoman, inspirasi, dan dukungan pada setiap anggota bangsa Indonesia dalam memperkembangkan dirinya sebagai bangsa Indonesia. Sedangkan pembaharuan yang sehat selalu bertitik tolak pada masa lampau dan sekaligus diarahkan bagi terwujudnya cita-cita di masa depan. Setiap zaman menampakkan corak kepribadiannya sendiri, namun kepribadian yang terbentuk pada zaman yang berbeda haruslah mempunyai kesinambungan dari masa lampau sampai masa mendatang sehingga tergambarkan aspek historitasnya (Hardono Hadi, 1994: 76). Kesinambungan tidak berarti hanya penggulangan atau pelestarian secara persis apa yang dihasilkan di masa lampau untuk diterapkan pada masa kini dan masa mendatang. Unsur yang sama dan permanen maupun unsur yang kreatif dan baru, semuanya harus dirajut dalam satu kesatuan yang integral. 
Teori hilemorfisme dari Aristoteles bisa mendukung pandangan tersebut. Aristoteles menegaskan, bahwa meskipun materi (hyle) menjadi nyata bila dibentuk (morfe), namun materi tidaklah pasif. Artinya ada gerak. Setiap relitas yang sudah berbentuk (berdasar materi) dapat juga menjadi materi bagi bentuk yang lain,sehingga setiap realitas mengalami perubahan. Perubahan yang ada bukan kebaharuan sama sekali namun perubahan yang kesinambungan. Artinya, aktualitas yang ada sekarang berdasar pada realitas yang telah ada pada masa lampau dan terbuka bagi adanya perubahan di masa depan.

\section{PENUTUP}

Dinamika dalam mengaktualisasikan nilai Pancasila ke dalam kehidupan bermasyarakat, berbangsa, dan benegara adalah suatu keniscayaan, agar Pancasila tetap selalu relevan dalam fungsinya memberikan pedoman bagi pengambilan kebijaksanaan dan pemecahan masalah dalam kehidupan berbangsa dan bernegara. Agar loyalitas warga masyarakat dan warganegara terhadap Pancasila tetap tinggi. Di lain pihak, apatisme dan resistensi terhadap Pancasila bisa diminimalisir.

Substansi dari adanya dinamika dalam aktualisasi nilai Pancasila dalam kehidupan praksis adalah selalu terjadinya perubahan dan pembaharuan dalam mentransformasikan nilai Pancasila ke dalam norma dan praktik hidup dengan menjaga konsistensi, relevansi, dan kontekstualisasinya. Sedangkan perubahan dan pembaharuan yang berkesinambungan terjadi apabila ada dinamika internal (self-renewal) dan penyerapan terhadap nilai-nilai asing yang relevan untuk pengembangan dan penggayaan ideologi Pancasila.Muara dari semua upaya perubahan dan pembaharuan dalam mengaktualisasikan nilai Pancasila adalah terjaganya akseptabilitas dan kredibilitas Pancasila oleh warganegara dan wargamasyarakat Indonesia.

\section{DAFTAR PUSTAKA}

Abdulkadir Besar. 1994. Pancasila dan Alam Pikiran Integralistik (Kedudukan dan Peranannya dalam Era Globalisasi). Yogyakarta: Panitia Seminar “Globalisasi Kebudayaan dan Ketahanan Ideologi" 16-17 November 1994 di UGM.

Bachtiar, Harsja W. (Peny.).1976. Percakapan dengan Sidney Hook tentang Masalah Filsafat. Jakarta: Jambatan.

Bakker, Anton.1992. Ontologi atau Metafisika Umum. Yogyakarta: Penerbit Kanisius.

Bertens. Kess. 1976. Ringkasan Sejarah Filsafat. Yogyakarta: Penerbit Yayasan Kanisius.

Bracher, Karl Dietrich. 1984. The Age of Ideologies. New York: St.Martin's Press.

Damardjati Supadjar.1990. Konsep Kefilsafatan tentang Tuhan Menurut Alfred Nort Whitehead. Yogyakarta: Disertasi Doktor di UGM.

Dibyasuharda. 1990.Dimensi Metafisik dalam Simbol: Ontologi mengenai Akar Simbol. Yogyakarta: Disertasi Doktor di UGM.

Driyarkara, N.1959. Pantjasila dan Religi. Yogyakarta: Makalah disampaikan pada Seminar Pantjasila I di Yogyakarta tanggal 16 sampai 20 Februari. .1993 (Cet.ke-12).Filsafat Manusia. Yogyakarta: Penerbit Kanisius.

Habermas, Jurgen.1990. Ilmu dan Teknologi sebagai Ideologi. Jakarta: LP3ES.

Habib Mustopo, M.1992. Ideologi Pancasila dalam Menghadapi Globalisasi dan Era Tinggal Landas. Bandungan-Ambarawa: Panitia Seminar dan Loka Karya Nasional MKDU Pendidikan Pancasila Dosen-dosen PTN/PTS dan Kedinasan Pada tanggal 29 - 30 September 1992.

Hardono Hadi, P. 1994.Hakikat dan Muatan Filsafat Pancasila. Yogyakarta: Penerbit Kanisius. Kansil, C.S.T.1971. Pancasila dan Undang-Undang Dasar 1945. Jakarta: Pradnya Paramita.

Kattsoff, Louis 0.1953. Elements of Philosophy. New York: The Ronald Press Comp.

Kendall, G.A. 1981. "Ideology: An Essay in Definition" dalam majalah Philophy Today No.25, hal. 262 
$-276$.

Koento Wibisono. 1988. Pancasila Ideologi Terbuka. Magelang: Panitia Temu Karya

Dosen-Dosen PTN Se-Jawa Tengah dan Kopertis Wil.VI.

Leahy, Louis. 1993. "Ideologi Tinjauan Historis dan Kritis". Yogyakarta: dalam Majalah Basis No.42, halaman $130-135$.

Liek Wilardjo. 1990.Realita dan Desiderata. Yogyakarta: Duta Wacana University Press.

Lorens Bagus. 1991. Metafiska. Jakarta: PT Gramedia.

Magnis Suseno, Franz. 1991. Berfilsafat dari Konteks. Jakarta: PT Gramedia.

Mannheim, Karl. 1991. Ideologi dan Utopia (Menyingkap Kaitan Pikiran dan Politik). Yogyakarta: Penerbit Kanisius.

Moerdino. 1995/1996. "Pancasila sebagai Ideologi Terbuka Menghadapi Era Globalisasi dan Perdagangan Babas", dalam Majalah Mimbar No.75 tahun XIII. 1995/1996. "Masalah Filsafati dan Ideologi dalam Membangun Negara Hukum di Indonesia", dalam Majalah Mimbar No. 74 tahun XIII.

Naisbitt, John dan Patricia Aburdence. 1990. Megatrends 2000 (Sepuluh Arah Baru untuk Tahun 1990-an). Jakarta: Bina Rupa Aksara.

Notonagoro. 1974 (Cet.Kelima). Beberapa Hal Mengenai Falsafah Pancasila. Jakarta: Universitas Pancasila.

1975. Pancasila secara Ilmiah Populer. Jakarta: Pantjuran Tudjuh. 1984 (Cet.Keenam). Pancasila Dasar Falsafah Negara. Jakarta: Bina Aksara.

Popkin, Richard, dan Avrum Stroll. 1958. Philosophy Made Simple. New York: Made

Sample Books, Inc.

Pranarka A.M.W. 1985. Sejarah Pemikiran tentang Pancasila. Jakarta: CSIS.

Sartono Kartodirdjo. 1990. Kebudayaan Pembangunan dalam Perspektif Sejarah. Yogyakarta: Gadjah Mada University Press.

Sastrapratedja,M. 1996. Pancasila dan Globalisasi. Magelang: Panitia Seminar Nasional Pendidikan Pancasila di Universitas Tidar pada 29-31 Juli 1996.

Slamet Sutrisno. 1986. Pancasila sebagai Metode. Yogyakarta: Liberty.

Snyder, Louis L. 1954. The Meaning of Nationalism. New Brunswick-New Jersey: Rutger University Press.

Soedjati Djiwandono, J. 1995. Setengah Abad Negara Pancasila (Tinjauan Kritis ke Arah Pembaharuan. Jakarta: CSIS.

Soerjanto Poespowardojo. 1989. Filsafat Pancasila. Jakarta: Gramedia. Sudarmanto, JB. 1987. Agama dan Ideologi. Yogyakarta: Penerbit Kanisius.

Sudarminta, J. 1991. Filsafat Proses (Sebuah Pengantar Sistematik Filsafat Whitehead).Yogyakarta: Penerbit Kanisius.

Suwarno, P.J. 1993. Pancasila Budaya Bangsa Indonesia. Yogyakarta: Penerbit Kanisius.

Traer, Robert. 1991. Faith in Human Rights. Washington DC: Georgetown Univ.Press.

Whitehead, Alfred North. 1979. Process and Reality. New York: The Free Press.

William Ebenstein \& Edwin Fogelman. 11985. Today's Isms. London: Prentice-Hall,Inc. 